\title{
REVIEW
}

\section{The GH/IGF1 axis and signaling pathways in the muscle and bone: mechanisms underlying age-related skeletal muscle wasting and osteoporosis}

\author{
Sebastio Perrini, Luigi Laviola, Marcos C Carreira, Angelo Cignarelli, Annalisa Natalicchio \\ and Francesco Giorgino \\ Section of Internal Medicine, Endocrinology, Andrology and Metabolic Diseases, Department of Emergency and Organ Transplantation, University of Bari \\ School of Medicine, Piazza Giulio Cesare, 11, I-70124 Bari, Italy \\ (Correspondence should be addressed to F Giorgino; Email: f.giorgino@endo.uniba.it)
}

\begin{abstract}
The widespread increase in life expectancy is accompanied by an increased prevalence of features of physical frailty. Signs and symptoms may include sarcopenia and osteopenia, reduced exercise capacity, and diminished sense of wellbeing. The pathogenesis of age-associated sarcopenia and osteopenia is multifactorial, and hormonal decline may be a contributing factor. Aging is associated with a progressive decrease in $\mathrm{GH}$ secretion, and more than $30 \%$ of elderly people have circulating IGF1 levels below the normal range found in the young. GH acts directly on target tissues, including skeletal muscle and bone among many others, but many effects are mediated indirectly by circulating
\end{abstract}

(liver-derived) or locally produced IGF1. Aging is also associated with reduced insulin sensitivity which, in turn, may contribute to the impairment of IGF1 action. Recent experimental evidence suggests that besides the agedependent decline in GH and IGF1 serum levels, the dysregulation of GH and IGF1 actions due to impairment of the post-receptor signaling machinery may contribute to the loss of muscle mass and osteopenia. This article will focus on the molecular mechanisms of impaired GH and IGF1 signaling and action in aging, and their role in the pathogenesis of sarcopenia and osteoporosis.

Journal of Endocrinology (2010) 205, 201-210

\section{Introduction}

Age-related muscle wasting and sarcopenia are characterized by the loss of skeletal muscle mass with a gradual decline in muscle function, including a decrease in power-producing capacity, contraction, and relaxation, but also by metabolic abnormalities, including reduced insulin sensitivity, impaired oxidative defense, and decreased mitochondrial function (Dela \& Kjaer 2006). During aging, the loss of muscle mass and strength is due to progressive atrophy, loss of muscle fibers, and reduction in muscle capacities. Although these changes are, to some extent, the consequence of the reduced level of physical activity, they can also be influenced by biological processes, including infiltration of fat and connective tissue into the muscle, changes in muscle metabolism, insulin resistance, reduced levels of specific hormones, and the oxidative stress accumulated during the lifespan (Cree et al. 2004, Hagen et al. 2004). The oxidative stress leads to mitochondrial DNA mutations resulting in dysfunctional mitochondria, and this promotes a reduced efficiency of skeletal muscle, which is particularly susceptible to this biological phenomenon (Hagen et al. 2004). When muscle activity is reduced, metabolites and survival factors that are normally stored in the muscle are no longer available. In addition, aging is typically associated with bone loss, leading to bone fragility and increased risk for osteoporosis and fractures. In fact, age-related wasting may coexist with osteoporosis, establishing a vicious circle between dysfunctional muscle and bone.

GH regulates important physiological processes, including somatic growth and development (Giustina et al. 2008), as well as carbohydrate and lipid metabolism (Perrini et al. 2008a,b, Møller et al. 2009), directly through the activation of specific GH receptors (GHRs; Giustina et al. 2008), or indirectly through insulin-like growth factor 1 (IGF1; Laviola et al. 2007), which is produced mainly in the liver in response to GH stimulation (Ohlsson et al. 2009; Fig. 1). IGF1 is also produced by a variety of cell types, and acts in a paracrine fashion in most tissues (see below). Circulating GH levels decline progressively after 30 years of age at a rate of $\sim 1 \%$ per year (Hermann \& Berger 2001). In the skeletal muscle, GH promotes cell growth by favoring the fusion of myogenic 


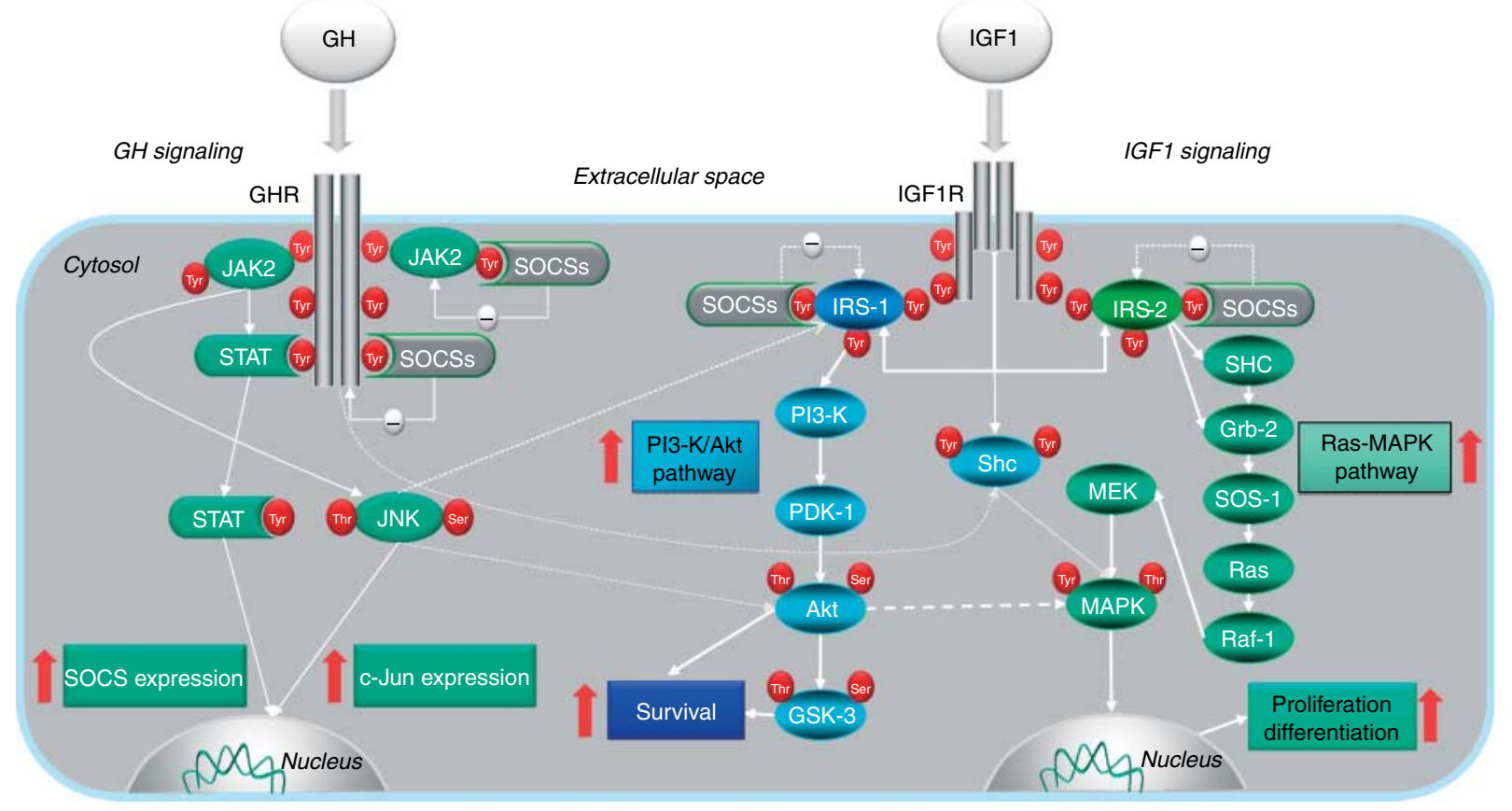

Figure $1 \mathrm{GH}$ and IGF1 signaling and action in skeletal muscle and osteoblastic cells. Individual signaling molecules with the phosphorylated amino acid residues are indicated. GHR, GH receptor. IGF1R, insulin growth factor 1 receptor.

precursor cells into existing myotubes, and this requires the IGF1-independent activation of nuclear factor of activated T-cell C2 (Sotiropoulos et al. 2006). Acute administration of $\mathrm{GH}$ regulates muscle mitochondrial function by increasing the levels of several key mitochondrial proteins, and by switching fuel utilization toward fat oxidation (Short et al. 2008). In addition, exogenous administration of IGF1 induces an increase in muscle oxidative enzymes and fatigue resistance (Schertzer et al. 2006). In bone, both GH and IGF1 are essential for the development and growth of the skeleton and maintenance of bone mass. IGF1, which mediates most of the effects of $\mathrm{GH}$ on skeletal metabolism, promotes chondrogenesis and increases bone formation by regulating the functions of the differentiated osteoblasts (Giustina et al. 2008).

This review will summarize current information on the mechanisms and intracellular signaling involved in the development of age-related changes in muscle mass and bone. In addition, the specific role of the GH/IGF1 system in the pathogenesis of age-related skeletal muscle wasting and osteoporosis will be discussed.

\section{Regulation of the GH/IGF1 axis during aging}

\section{GH}

$\mathrm{GH}$ is a single-chain peptide of 191 amino acids produced and secreted mainly by the somatotrophs of the anterior pituitary gland (Davidson 1987). GH secretion occurs in a pulsatile manner with a major surge at the onset of slow-wave sleep and less conspicuous secretory episodes a few hours after meals (Ho et al. 1988, Hartman et al. 1991), and is controlled by the action of two hypothalamic factors, GHRH, which stimulates GH secretion, and somatostatin, which inhibits $\mathrm{GH}$ secretion (Giustina et al. 2008). During fasting, GH secretion is amplified, whereas excess of glucose and lipids inhibits $\mathrm{GH}$ release (Ho et al. 1988). In addition, different stimuli, including gender, age, adiposity, sleep, diet, and exercise, affect the frequency and magnitude of the $\mathrm{GH}$ pulses. The secretion of $\mathrm{GH}$ is maximal at puberty accompanied by very high circulating IGF1 levels (Moran et al. 2002), with a gradual decline during adulthood (Corpas et al. 1993). Indeed, in aged men, daily GH secretion is 5- to 20-fold lower than that in young adults (Ryall et al. 2008). The age-dependent decline in GH secretion is secondary to a decrease in GHRH, and to an increase in somatostatin secretion (Veldhuis \& Iranmanesh 1996). These changes occur at the hypothalamic level, although their cause is still unknown. As a consequence of the decline in GH synthesis and release, systemic IGF1 levels decline with advancing age (Landin-Wilhelmsen et al. 1994). The changes in GH and IGF1 secretion that occur with aging are paralleled by a progressive loss of muscle mass and bone mineral density (BMD; Bohannon 1997). Overload and stretch-dependent IGF1 and IGF2 production in the skeletal muscle has been found to be impaired in older humans (Hameed et al. 2004).

In addition, in the last 10 years, several studies have demonstrated a significant inverse relationship between peak stimulated GH levels and body mass index (BMI; Bonert et al. 2004, Corneli et al. 2005, Franco et al. 2006). Multiple lines 
of evidence indicate that apparently healthy overweight and obese subjects meet standard diagnostic criteria used to diagnose GH deficiency (GHD) in hypopituitarism (Johannsson \& Bengtsson 1999). On the other hand, the role of the peripheral fat in impairing the regular pattern of $\mathrm{GH}$ release was recently shown in postmenopausal women with abdominal obesity. In this clinical context, the pulsatile GH secretion was negatively associated with the amount of thigh intermuscular adipose tissue, whereas basal $\mathrm{GH}$ secretion demonstrated an independent negative association with visceral adipose tissue (Franco et al. 2006). Furthermore, Møller et al. (2009) have recently shown that lipid infusion during $\mathrm{GH}$ stimulation decreases signal transducer and activator of transcription 5 (STAT5) phosphorylation (the major target of $\mathrm{GH}$ intracellular signaling) by about $40 \%$, an effect that was evident already at low lipid infusion rates. This suggests that whenever free fatty acid (FFA) levels are high, e.g. during fasting/protracted exercise, dyslipidemia, excess body fat, type 2 diabetes, or inflammatory illness, the activation of intracellular GH signaling and its related growth-promoting and anabolic effects are restricted. Thus, the direct correlation between high FFA levels and reduced intracellular GH signaling and action may be applied to subjects with central obesity and/or high BMI. Since recent studies have demonstrated a significant increase in BMI and visceral fat accumulation with aging (Rössner 2001, Hajian-Tilaki \& Heidari 2007), the reciprocal interplay of increasing BMI, central obesity, and FFA excess may be relevant to the age-dependent decline in $\mathrm{GH}$ secretion and action.

\section{Insulin-like growth factor 1}

IGF1 is perhaps the most important mediator of muscle and bone growth (Goldspink 2007). Systemic IGF1 is synthesized primarily in the liver, where its synthesis is $\mathrm{GH}$ dependent; IGF1 is also produced in multiple extrahepatic tissues, where it acts locally as an autocrine/paracrine growth factor under the control of multiple hormones (Laviola et al. 2007). The IGFs, including IGF1 and IGF2, are single-chain polypeptides, which share a similar secondary structure, with three $\boldsymbol{\alpha}$-helices and three disulfide bonds (Mathews et al. 1986). Despite a significant structural similarity, each ligand can result in unique signaling outcomes. As an example, IGF2 is unable to compensate for the loss of IGF1 activity in patients with IGF1 deficiency, leading to severe growth and mental retardation (Chen et al. 2001). Similarly, mice with targeted disruption of the IGF1 or IGF2 genes are born at $60 \%$ birth weight compared with wild-type littermates (Baker et al. 1993). Although in rodents IGF2 is predominantly expressed in fetal life whereas IGF1 is considered an adult growth factor, this expression pattern is not observed in humans, as both ligands are produced in multiple human tissues throughout life, which is consistent with the concept that IGF1 and IGF2 have potentially divergent roles in human physiology (Rosenfeld \& Hwa 2009). It has been shown that IGF1 exists in at least two isoforms as a result of alternative splicing of the IGF1 gene. IGF1Ea, which is produced in both liver and muscle tissues, was the first isoform to be discovered and is often referred to as liver-type or systemic IGF1. IGF1Eb (rodent form) and IGF1Ec (human form) are produced mainly by the skeletal muscle, and are usually referred to as mechano growth factors (MGFs; Goldspink 2004). Unlike MGFs, liver-type IGF1 is glycosylated, and this modification protects it from proteolysis and confers a relatively long halflife. In addition, IGF1 half-life in plasma and the interaction of IGF1 with the IGF1 receptor (IGF1R) are regulated either positively or negatively by a family of six high-affinity IGF binding proteins (IGFBPs; IGFBP1 to IGFBP6; Laviola et al. 2007, Rosenfeld \& Hwa 2009). In tissues, IGFBPs can both inhibit or potentiate IGF1 actions either by sequestering IGF1 from the IGF1R or by releasing free IGF1 available for receptor binding. IGF1 is released from the complex by either proteolysis of IGFBPs or binding of IGFBPs to the extracellular matrix. IGFBP phosphorylation can also alter the affinity for the IGFs (Rosenfeld \& Hwa 2009). IGF-independent actions have also been recently described for most IGFBPs, and can involve intracellular localization or integrin binding (Woodhouse et al. 2006).

Unlike GH, serum IGF1 levels are stable without significant variability in healthy individuals. In contrast to $\mathrm{GH}$, the circulating IGF1 levels are reduced during fasting, and IGF1 infusion suppresses $\mathrm{GH}$ release, suggesting a negative feedback loop between the two hormones. Recently, in an 8-year prospective study conducted in elderly men, Brugts et al. (2008) have shown that higher circulating IGF1 bioactivity was associated with better overall survival, since individuals in the lowest quartile of IGF1 bioactivity had a $1 \cdot 8$-fold increased mortality risk compared with individuals in the highest quartile. Besides the age-dependent decline in GH and IGF1 serum levels, the increased mortality risk and diminished sense of well-being may be also due to the impairment of the GH and IGF1 post-receptor signaling machinery. In line with these findings, Dennis et al. (2008) have reported that median IGF1 and IGFBP5 mRNA levels in resting young muscle are more than twice higher than those in elderly muscle. In general, tissue responsiveness to IGF1 is altered with aging. Aging is associated with decreases in IGF1R content and IGF1R phosphorylation in muscle (Li et al. 2003). Furthermore, in fibroblasts, DNA synthesis and cell proliferation in response to IGF1 decrease with older age (Sell et al. 1993). Bone responsiveness to IGF1 also decreases with aging (Kveiborg et al. 2000). The skeletal anabolic response to IGF1 administration is weakened in the elderly, and biopsy-derived osteoblasts from patients of different ages respond to IGF1 by increasing proliferation, but the dose needed to elicit a response is an order of magnitude greater for cells from aged patients (Pfeilschifter et al. 1993). These studies suggest that low circulating IGF1 bioactivity and abnormalities of IGF1 signaling in elderly subjects, especially in those individuals with an age-related proinflammatory state (i.e. subjects with visceral or central obesity), may play an important role in age-related sarcopenia and osteopenia (Fig. 2). 


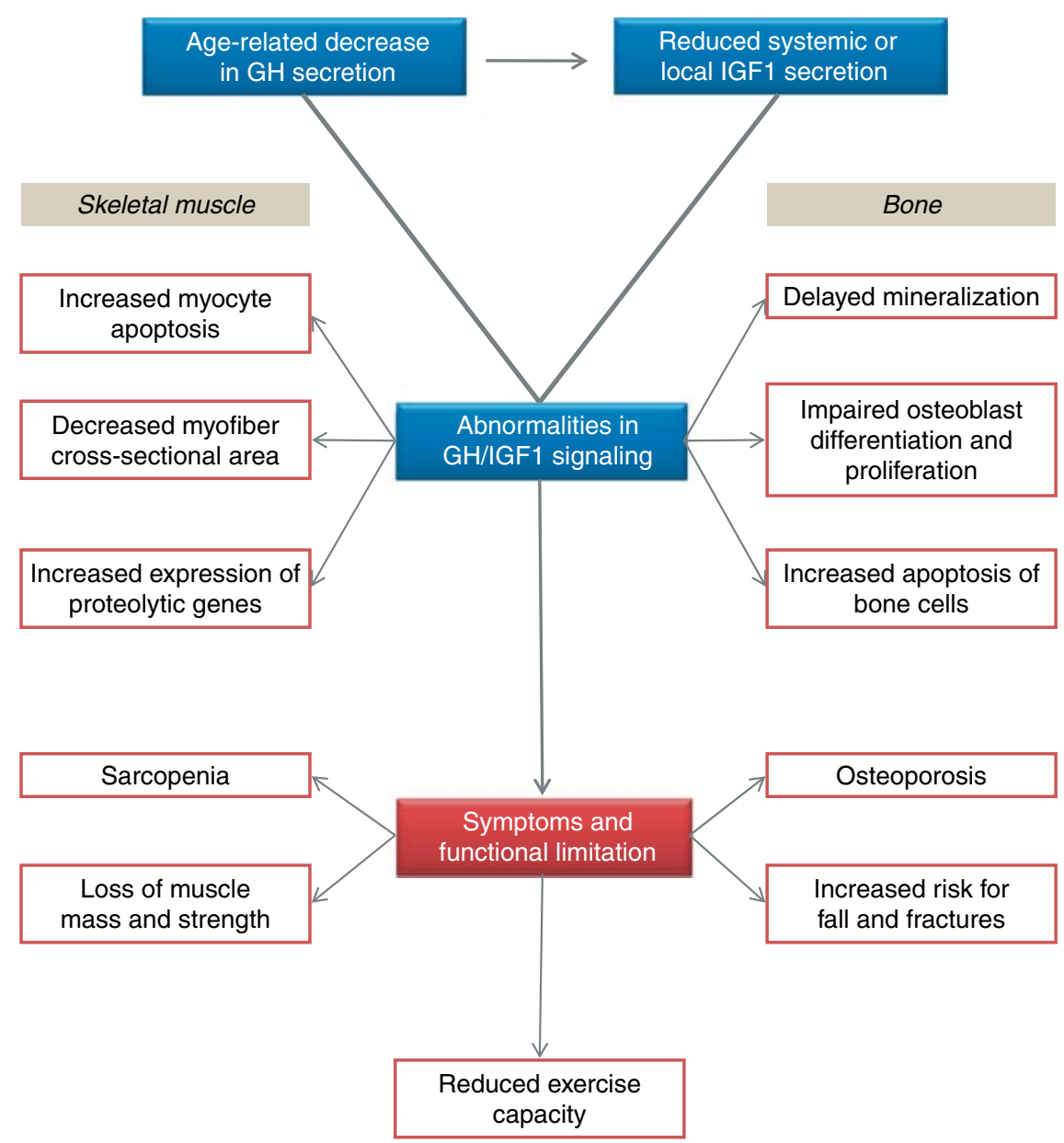

Figure 2 A schematic model of the mechanisms leading to sarcopenia, osteoporosis, physical impairment, and functional limitations and disabilities in aging subjects.

\section{GH intracellular signaling}

GH effects are mediated via the GHR, which is a member of the cytokine receptor superfamily. The critical step in initiating $\mathrm{GH}$ signaling is the activation of receptor-associated Janus kinase (JAK) 2, which induces cross-phosphorylation of tyrosine residues in the kinase domain of JAK2 and GHR (Fig. 1). Phosphorylated residues on JAK2 and GHR form docking sites for the members of the STAT family of transcription factors (Perrini et al. 2008b). Phosphorylation of the STATs by JAK2 results in their dissociation from the receptor and translocation to the nucleus, with subsequent binding to DNA and regulation of gene expression. Among the target genes, GH regulates the expression of suppressor of cytokine signaling (SOCS), a family of negative regulators that terminate the GH signaling cascade (Hansen et al. 1999). SOCS proteins bind to phosphotyrosine residues on the GHR or JAK2 and suppress GH signaling by inhibiting JAK2 activity, competing with STATs for binding to the GHR, or inducing degradation of the GHR complex (Fig. 1).
The RAS/mitogen-activated protein kinase (MAPK) pathway has also been shown to be activated by GH. The GHR-JAK2 complex has been shown to recruit the adapter protein SHC, resulting in SHC tyrosine phosphorylation and binding to GRB2, and activation of RAS, RAF, MAPK/ extracellular-regulated protein kinase (MEK), and ERK-1/2 (Vanderkuur et al. 1997; Fig. 1). Alternatively, it has been suggested that GH might also regulate the activation of ERK$1 / 2$ by a SRC-dependent, JAK2-independent mechanism which involves phopholipase D (Zhu et al. 2002). Tyrosine phosphorylation of a GRB2-binding site in the epidermal growth factor receptor could also be involved in $\mathrm{GH}-$ mediated MAPK activation (Yamauchi et al. 1997).

GH has also been shown to stimulate the phosphatidylinositol 3-kinase (PI3-K) pathway through JAK2-mediated tyrosine phosphorylation of the insulin receptor substrates (IRS-1 to IRS-3), leading to their association with PI3-K regulatory subunits (Zhu et al. 2001). In addition, direct binding of the $\mathrm{p} 85 \alpha$ and $\mathrm{p} 85 \beta$ subunits to phosphotyrosine residues in the carboxyl terminus domain of the GHR 
has also been demonstrated (Moutoussamy et al. 1998). GH stimulation of PI3-K is linked to the stimulation of the antiapoptotic serine protein kinase B or AKT (Costoya et al. 1999). Akt activation has been shown to be dependent on the presence of the JAK2-binding region of GHR, and to promote cell survival through the inhibition of the proapoptotic protein caspase 3 (Sanders et al. 2006).

\section{IGF1 intracellular signaling}

Most biological actions of IGF1 are mediated through the type I IGF receptor (IGF1R), which is a transmembrane tyrosine kinase that is structurally and functionally related to the IR. Both receptors show a heterotetrameric structure (two $\alpha$-subunits and two $\beta$-subunits), with an extracellular hormone-binding domain, a transmembrane region, and an intracellular portion, which contains the kinase domain and multiple regulatory residues. Upon ligand binding, the intrinsic tyrosine kinase of the IGF1R is activated, and this results in autophosphorylation of tyrosine residues in the intracellular portion of the $\beta$-subunit, including tyrosine residues in the juxtamembrane and C-terminal domains. Once phosphorylated, tyrosine 950 in the juxtamembrane domain can serve as a docking site for several receptor substrates, including the IRSs and Shc (Laviola et al. 2008). These substrates initiate phosphorylation cascades that serve to transmit the IGF1R signal (Fig. 1). Phosphorylated IRS-1 can activate the p85 regulatory subunit of PI3-K, leading to the activation of several downstream substrates, including Akt (Giorgetti et al. 1993). AKT phosphorylation, in turn, enhances protein synthesis through mechanistic target of rapamycin (MTOR) and p70S6 kinase activation, and mediates the antiapoptotic effects of the IGF1R through phosphorylation and inactivation of BAD (Petley et al. 1999). In parallel to PI3K-driven signaling, recruitment of GRB2/SOS by phosphorylated IRS-1 or SHC leads to recruitment of Ras and activation of the RAF-1/MEK/ERK pathway and downstream nuclear factors, resulting in the induction of cell proliferation (Fig. 1; Grey et al. 2003). Shc may actually compete with IRS-1 for a limited cellular pool of GRB2, and the extent of SHC/GRB2 binding appears to correlate with the amount of insulinactivated ERK and c-fos transcription (Yamauchi \& Pessin 1994). Therefore, the SHC/GRB2 pathway represents the predominant mechanism activating the RAS/ERK signaling pathway in response to IGF1. Recent experimental evidence has shown that distinct SHC isoforms exert opposite effects on the ERK signaling cascade. The SHC proteins originate by alternative use of three distinct translation starting points on a longer transcript ( $\mathrm{p} 46^{\text {Shc }}, \mathrm{p} 52^{\text {Shc }}$, and $\mathrm{p} 66^{\text {Shc }}$ ) and two translation starting points on a shorter transcript $\left(\mathrm{p} 46^{\text {Shc }}\right.$ and p5 $2^{\text {Shc }}$ ); the two mRNA transcripts are generated by alternative splicing from a single gene (Pelicci et al. 1992, Natalicchio et al. 2004). Although all three SHC isoforms can be tyrosine phosphorylated upon growth factor stimulation, $\mathrm{p} 46 / \mathrm{p} 52^{\text {Shc }}$ transduce growth and survival signals, whereas $\mathrm{p} 66^{\text {Shc }}$ is also modified by serine phosphorylation and plays an important role in mediating oxidative stress-dependent cell damage and apoptosis (Migliaccio et al. 1999). Indeed, the p66 ${ }^{\text {Shc }}$ protein has been shown to regulate intracellular oxidant levels and hydrogen peroxide-mediated forkhead inactivation (Nemoto \& Finkel 2002), effects that are probably relevant to the reported ability of $\mathrm{p} 66^{\text {Shc }}$ to control lifespan in mammals (Migliaccio et al. 1999). Furthermore, while $\mathrm{p} 46 / \mathrm{p} 52^{\text {Shc }}$ trigger the activation of the ERK pathway via GRB2/SOS/RAS, p66 $6^{\text {Shc }}$ exerts an inhibitory effect on ERK, because reduced $\mathrm{p} 66^{\text {Shc }}$ expression levels are associated with persistent ERK activation (Natalicchio et al. 2004). The opposite regulation of ERK effects by $\mathrm{p} 46 / \mathrm{p} 52^{\text {Shc }}$ and $\mathrm{p} 66^{\text {Shc }}$ respectively may be physiologically relevant, since human breast cancer tissues with high $\mathrm{p} 46 / \mathrm{p} 52^{\text {Shc }}$ to $\mathrm{p} 66^{\text {Shc }}$ expression ratios are characterized by increased cell proliferation and poor prognosis (Davol et al. 2003).

\section{Abnormalities in GH/IGF1 signaling and age-related muscle mass wasting}

Age-related skeletal muscle wasting affects all elderly subjects by impairing their functional independence and increasing their risk for falls and fractures (Szulc et al. 2005). It has been suggested that during aging, the loss of muscle mass and strength is due to the progressive atrophy, decrease in myofiber cross-sectional area (CSA), loss of muscle fibers (Ryall et al. 2008), and reduction in muscle capacities (Szulc et al. 2005). An age-related reduced efficiency of the multistep GH/IGF signaling machinery may also play a role in the reduced skeletal muscle structure and function. Indeed, reduced mRNA expression levels of the GHR in skeletal muscle have been observed in older versus younger healthy men, exhibiting a significant negative relationship with myostatin levels (Marcell et al. 2001). Myostatin functionally impairs satellite cell (myoblast) activity by inhibiting protein and DNA synthesis and cell proliferation (Taylor et al. 2001), and counteracting GH-dependent promotion of muscle protein synthesis and activation of satellite cells (Marcell et al. 2001). In addition, myostatin null mutations (Zhu et al. 2000) and gene knockout experiments (McPherron et al. 1997) result in a significant increase in muscle mass. Thus, the observed increased expression of muscle myostatin with aging may be due, at least in part, to the age-related decrease in endogenous $\mathrm{GH}$, contributing to age-related sarcopenia. It has also been shown that mice lacking $\operatorname{GHR}\left(\mathrm{GHR}^{-/-}\right)$ exhibit proportional growth retardation and delayed and/or diminished responses in IRS-1 phosphorylation following in vivo insulin stimulation in muscle (Robertson et al. 2006). Dysregulation of the IRS/PI3-K/AKT pathway appears to be particularly relevant to the development of age-related muscle wasting, because in vitro studies have implicated this signaling pathway in myocyte growth and muscle mass regulation (Rommel et al. 2001). Skeletal muscle biopsies from older male subjects show a reduction in the CSA of type II muscle 
fibers by $40-45 \%$, in parallel with a $45 \%$ decreased GHR protein and IGF1 mRNA levels, as well as increased TNF- $\alpha$ and SOCS-3 mRNA levels, when compared with younger donors (Léger et al. 2008). Furthermore, total AKT, but not phosphorylated AKT, proteins levels are increased by $2 \cdot 5$-fold, resulting in a $30 \%$ reduction in the efficiency of AKT phosphorylation in older subjects. Indeed, multiple studies have shown that SOCS-3 has been casually linked to insulin resistance either by associating with the IR and suppressing its tyrosine kinase activity, or by decreasing IRS phosphorylation and downstream signaling reactions. Deletion of PI3-K in the muscle per se results in decreased muscle size and inefficient muscle metabolism (Luo et al. 2006), and the inhibition of PI3-K or AKT prevents the anabolic effects of IGF1 in cultured cells (Giorgino et al. 1997). In fact, an age-related deficit in IGF1R activation has been demonstrated in the muscle of old rats, and this was associated with a reduced activity of the IRS-1/PI3-K pathway (Haddad \& Adams 2006). Conversely, AKT hyperactivation leads to muscle hypertrophy in vivo (Lai et al. 2004). At the molecular level, myocyte growth is thought to be promoted by AKT signaling through MTOR and GSK-3 (Bodine et al. 2001, Rommel et al. 2001). In addition, AKT-mediated phosphorylation of forkhead transcription factors results in reduced expression of atrogin-1 (also known as MAFbx or FBXO) and MuRF1, two $\mathrm{E} 3$ ubiquitin ligases that promote muscle protein degradation (Sandri et al. 2004). More recently, an impaired AKT kinase activity in myocytes has been found to be associated with higher levels of apoptosis, lower abundance of the contractile proteins myosin and actin, and a smaller muscle fiber CSA (Wu et al. 2009). Interestingly, the restoration of AKT kinase activity was associated with increased amount of contractile proteins and myocyte size, and decreased apoptotic rates. More limited studies are available in humans. Recently, a reduced effect of insulin on leg protein breakdown has been observed in older versus younger subjects, and this appears to be associated with blunted AKT activation (Wilkes et al. 2009).

In conclusion, the age-associated reduction in $\mathrm{GH}$ and IGF1 plasma levels, and their reduced intracellular signaling efficiency are associated with decreased muscle size and strength, diminished protein synthesis, and increased cell apoptosis. Therefore, age-related human sarcopenia may be linked to impaired activation of anabolic signaling pathways emanating from the GHR and IGF1R and involving the IRSs, PI3-K, and AKT (Fig. 2).

\section{Abnormalities in GH/IGF1 signaling and age-related osteoporosis}

The GH/IGF1 axis provides the main stimulus for bone growth regulation by activating the osteoblast differentiation program, stimulating chondrocyte proliferation at the growth plate, and modulating tubular re-absorption of phosphate and 25-hydroxyvitamin D3 $1 \alpha$-hydroxylase activity in the kidney (Giustina et al. 2008). Consistent with these findings, a decline in GH and IGF1 secretion has been correlated with BMD loss in postmenopausal women; in addition, IGF1 promoter polymorphisms have been linked to bone mass (Zhao et al. 2008). GH stimulates the proliferation of cells of the osteoblastic lineage, although IGF1 is required for the selected anabolic lineage (Slootweg et al. 1988), suggesting either a direct effect of $\mathrm{GH}$ on chondrocytes or an effect mediated by the locally secreted IGF1. Indeed, GHR null mice exhibit decreased bone remodeling, which is rescued by IGF1, suggesting a role of GH/IGF1 in bone remodeling that is independent of STAT5. The fundamental role of IGF1 in regulating bone formation is demonstrated by the analysis of IGF1-deficient mice, which exhibit skeletal malformations, delayed mineralization, reduced chondrocyte proliferation, and increased chondrocyte apoptosis (Laviola et al. 2008). The expression of functional IGF1R and GHRs mediating effects on cell proliferation and differentiation has been reported in cultured human osteoblast-like cells (Nilsson et al. 1995) and in clonal rat and mouse osteoblast-like cell lines (Slootweg et al. 1996). In addition, it has been shown that IGF1 treatment is effective in inducing gene expression of osteoblastic markers independent of age, identifying exogenous IGF1 as a potential beneficial treatment in age-related bone loss (Tanaka et al. 1994). IGF1R expression has also been demonstrated in mature rabbit osteoclasts, as well as in human pre-osteoclasts (Hou et al. 1997), and IGF1 enhances the formation of osteoclast-like cells in long-term bone marrow cultures (Jonsson et al. 1996). In contrast, IGF1 has an inhibitory effect on stimulated bone resorption in bone organ cultures (Jonsson et al. 1996). Osteoblasts also produce IGFBPs, dependent upon the stage of maturation and stimulation with GH or IGFs. These IGFBPs regulate GH and IGF responses by modulating receptor expression and bioavailability of IGF1 and IGF2. IGFBP2 is important as a circulating carrier of IGFs, and IGFBP2 serum levels correlate with BMD and turnover in humans (Amin et al. 2004). The effects of IGFBP2 are complex: female igfbp 2 null mice have increased cortical bone, whereas male igfbp 2 null mice display decreased cortical and trabecular bone secondary to decreased bone formation (DeMambro et al. 2008). These observations suggest that IGFBP2 is required for normal bone formation in male mice, and are in agreement with clinical observations indicating a correlation between serum IGFBP2 levels following the administration of IGF2/IGFBP2 and bone remodeling and anabolic effects in disuse osteoporosis (Amin et al. 2007). It is also of interest that mechanical loading upregulates the expression of IGF1 and IGFBP2 mRNA transcripts in osteocytes (Reijnders et al. 2007). The IGFs increase collagen production, and are incorporated into bone matrix bound to IGFBP5. During osteoclastic resorption, IGF1 and IGF2 are released and may again regulate osteoblastic functions, thereby coupling bone resorption and formation. Finally, GH, IGFs, and IGFBPs may all regulate osteoclastic bone resorption through direct and indirect effects on osteoclast differentiation and activation. 
IGF1 action on bone cells requires the integrity of the IGF1R signaling pathway (Fig. 1). As an example, both IRS-I and IRS-2 are expressed in osteocytes (Yamauchi et al. 1997). It has been proposed recently that IRS-2 is needed to maintain the predominance of bone formation over bone resorption, whereas IRS-1 maintains bone turnover, and that the integration of these two signals mediates a potent anabolic response to IGF1 in the bone (Ogata et al. 2000, Akune et al. 2002). The PI3-K/AKT pathway is utilized by IGF1 to decrease osteoblast apoptosis. Sustained activation of ERK-1 and ERK-2 by IGF1 is also important for the regulation of osteoblast proliferation (Zhang et al. 1999, Grey et al. 2003), whereas other MAP kinase family members, such as JNK and p38, seem to play a minor role (Grey et al. 2003). Abnormalities in IGF1 action and signaling occur in human osteoblasts under conditions of net bone loss. Individuals with insulin deficiency, as exemplified by type 1 diabetic patients, are susceptible to develop osteoporosis (Krakauer et al. 1997). Patients with Laron's syndrome caused by IGF1 deficiency are also prone to osteoporosis (Laron 1999). A reduction in IGF1 levels is implicated as an important factor in the etiology of evolutional osteoporosis, especially of age-related bone loss (Nicolas et al. 1994, Rosen 2004). Interestingly, while it has been shown that recombinant human IGF1 (rhIGF1) administration increases osteoblast function in healthy females in whom IGF1 levels and bone turnover were decreased by short-term caloric deprivation (Grinspoon et al. 1996), rhIGF1 was ineffective in increasing BMD in women with postmenopausal osteoporosis (Ghiron et al. 1995). Thus, abnormalities in IGF1 signaling may be responsible for altered IGF1 action on osteoblasts in human osteoporosis. Recently, a comparative analysis of IGF1 signaling was carried out in primary cultures of human osteoblasts isolated from osteoporotic and control bone specimens (Perrini et al. 2008a,b). In the osteoblasts from osteoporotic bone, tyrosine phosphorylation of the IGF1R was found to be increased in the basal state, but it was poorly responsive to IGF1 stimulation. Augmentation of IGF1R phosphorylation in the basal state was associated with increases in tyrosine phosphorylation of IRS-2 and activation of ERK, which were also poorly responsive to IGF1 stimulation. By contrast, phosphorylation levels of IRS-1, AKT, and GSK-3 were similar in the basal state in control and osteoporotic osteoblasts, and showed an increase after IGF1 stimulation in both cell populations, albeit the response in the osteoporotic osteoblasts was lower. Specifically, phosphorylation of AKT on Ser473 and Thr308 following IGF1 stimulation was significantly reduced in osteoporotic cells compared with control cells, leading to decreased GSK-3 phosphorylation. The IGF1 signaling abnormalities in osteoporotic osteoblasts were associated with reduced DNA synthesis both under basal conditions and after stimulation with IGF1 (Perrini et al. 2008a,b). Therefore, abnormalities in IGF1 signaling may explain the impaired cell proliferation and decreased bone formation that occur in human osteoporosis (Fig. 2).
Further complexity is added to this scenario while considering the role of the insulin/IGF system throughout evolution. Indeed, strong similarities exist in the insulin/IGF1 signaling machinery in worms, flies, mammals, and humans. However, worms and flies have only one receptor for both hormones, whereas the vertebrates have at least three closely related receptors (Katic \& Kahn 2005). In addition, studies in invertebrates suggest that insulin/GH/IGFs control lifespan. In fact, the impairment of the GH/IGF1 signaling has been correlated with extended longevity in worms, flies, and transgenic rodent models (Berryman et al. 2008). These observations are apparently in contrast with the abovedescribed effects of reduced GH/IGF1 action on muscle strength and trabecular bone mass; however, the complete removal of $\mathrm{GH}$ action by disrupting or knocking out the GHR gene $\left(\mathrm{GHR}^{-/-}\right)$in rodents (which resulted in $\mathrm{GH}$ resistance, elevated GH levels, and markedly reduced IGF1 levels) determined both a significant increase in lifespan and reduced muscle mass and BMD compared with littermate controls (Berryman et al. 2008). Thus, the insulin/GH/IGF signaling systems are involved in an integrated interplay between anabolic and life-cycle-controlling mechanisms.

\section{Conclusions}

The GH and IGF1 signaling pathways are important regulators of muscle and bone cell survival and function. The commonly observed decline in circulating GH and IGF1 levels that accompanies aging may contribute to reduced muscle strength and trabecular bone mass. Indeed, multiple long-term GH replacement trials, with a duration of at least 5 years, have shown that $\mathrm{GH}$ protects against the normal agerelated decline in muscle strength, neuromuscular function, and bone mass (Gibney et al. 1999, Svensson et al. 2003, Götherström et al. 2005). However, in elderly GHD adults above 60 years of age, the main effect of $\mathrm{GH}$ replacement seems to be a prevention of the age-related decline in muscle efficiency, rather than a significant increase in absolute values of muscle strength. In line with these observations, a recent 10-year GH replacement trial in GHD adults has shown that the increased muscle strength and improved neuromuscular function are more evident in younger subjects than in older subjects (Götherström et al. 2009). In addition, subjects receiving $\mathrm{GH}$ demonstrated no significant changes in BMD (Fernholm et al. 2000, Hoffman et al. 2004). The reduced effect on BMD and muscle strength noted in elderly subjects during prolonged $\mathrm{GH}$ replacement therapy suggests that other mechanisms, including abnormalities of the GH/IGF1 signaling in muscle and bone cells, may contribute to agerelated muscle wasting and osteoporosis. The identification of distinct abnormalities in GH/IGF1 signaling contributing to impaired cell proliferation and decreased functional efficiency in the muscle-bone system with aging may help to identify novel therapeutic targets for improving health and quality of life in aged humans. 


\section{Declaration of interest}

The authors declare that there is no conflict of interest that could be perceived as prejudicing the impartiality of the research reported.

\section{Funding}

This work was supported by grants from the Ministero dell'Università e Ricerca (MUR), Italy, and the University of Bari.

\section{References}

Akune T, Ogata N, Hoshi K, Kubota N, Terauchi Y, Tobe K, Takagi H, Azuma Y, Kadowaki T, Nakamura K et al. 2002 Insulin receptor substrate-2 maintains predominance of anabolic function over catabolic function of osteoblasts. Journal of Cell Biology 159 147-156.

Amin S, Riggs BL, Atkinson EJ, Oberg AL, Melton LJ III \& Khosla S 2004 A potentially deleterious role of IGFBP-2 on bone density in aging men and women. Journal of Bone and Mineral Research 19 1075-1083.

Amin S, Riggs BL, Melton LJ III, Achenbach SJ, Atkinson EJ \& Khosla S 2007 High serum IGFBP-2 is predictive of increased bone turnover in aging men and women. Journal of Bone and Mineral Research 22 799-807.

Baker J, Liu JP, Robertson EJ \& Efstratiadis A 1993 Role of insulin-like growth factors in embryonic and postnatal growth. Cell 75 73-82.

Berryman DE, Christiansen JS, Johannsson G, Thorner MO \& Kopchick JJ 2008 Role of the GH/IGF-1 axis in lifespan and healthspan: lessons from animal models. Growth Hormone \& IGF Research 18 455-471.

Bodine SC, Stitt TN, Gonzalez M, Kline WO, Stover GL, Bauerlein R, Zlotchenko E, Scrimgeour A, Lawrence JC, Glass DJ et al. 2001 Akt/mTOR pathway is a crucial regulator of skeletal muscle hypertrophy and can prevent muscle atrophy in vivo. Nature Cell Biology 3 1014-1019.

Bohannon RW 1997 Comfortable and maximum walking speed of adults aged 20-79 years: reference values and determinants. Age and Ageing $\mathbf{2 6}$ 15-19.

Bonert VS, Elashoff JD, Barnett P \& Melmed S 2004 Body mass index determines evoked growth hormone $(\mathrm{GH})$ responsiveness in normal healthy male subjects: diagnostic caveat for adult GH deficiency. Journal of Clinical Endocrinology and Metabolism 89 3397-3401.

Brugts MP, Ranke MB, Hofland LJ, van der Wansem K, Weber K, Frystyk J, Lamberts SWJ \& Janssen JAMJL 2008 Normal values of circulating insulinlike growth factor-I bioactivity in the healthy population: comparison with five widely used IGF-I immunoassays. Journal of Clinical Endocrinology and Metabolism 93 2539-2545.

Chen XL, Lee K, Hartzell DL, Dean RG, Hausman GJ, McGraw RA, Della-Fera MA \& Baile CA 2001 Adipocyte insensitivity to insulin in growth hormone-transgenic mice. Biochemical and Biophysical Research Communications 283 933-937.

Corneli G, Di Somma C, Baldelli R, Rovere S, Gasco V, Croce CG, Grottoli S, Maccario M, Colao A, Lombardi G et al. 2005 The cut-off limits of the GH response to GH-releasing hormone-arginine test related to body mass index. European Journal of Endocrinology 153 257-264.

Corpas E, Blackman MR, Roberson R, Scholfield D \& Harman SM 1993 Oral arginine-lysine does not increase growth hormone or insulin-like growth factor-I in old men. Journal of Gerontology 48 M128-M133.

Costoya JA, Finidori J, Moutoussamy S, Seãris R, Devesa J \& Arce VM 1999 Activation of growth hormone receptor delivers an antiapoptotic signal: evidence for a role of Akt in this pathway. Endocrinology 140 5937-5943.

Cree MG, Newcomer BR, Katsanos CS, Sheffield-Moore M, Chinkes D, Aarsland A, Urban R \& Wolfe RR 2004 Intramuscular and liver triglycerides are increased in the elderly. Journal of Clinical Endocrinology and Metabolism 89 3864-3871.

Davidson MB 1987 Effect of growth hormone on carbohydrate and lipid metabolism. Endocrine Reviews 8 115-131.
Davol PA, Bagdasaryan R, Elfenbein GJ, Maizel AL \& Frackelton ARJ 2003 Shc proteins are strong, independent prognostic markers for both nodenegative and node-positive primary breast cancer. Cancer Research $\mathbf{6 3}$ 6772-6783.

Dela F \& Kjaer M 2006 Resistance training, insulin sensitivity and muscle function in the elderly. Essays in Biochemistry 42 75-88.

DeMambro VE, Clemmons DR, Horton LG, Bouxsein ML, Wood TL, Beamer WG, Canalis E \& Rosen CJ 2008 Gender-specific changes in bone turnover and skeletal architecture in igfbp-2-null mice. Endocrinology 149 2051-2061.

Dennis RA, Przybyla B, Gurley C, Kortebein PM, Simpson P, Sullivan DH \& Peterson CA 2008 Aging alters gene expression of growth and remodeling factors in human skeletal muscle both at rest and in response to acute resistance exercise. Physiological Genomics 32 393-400.

Fernholm R, Bramnert M, Hägg E, Hilding A, Baylink DJ, Mohan S \& Thorén M 2000 Growth hormone replacement therapy improves body composition and increases bone metabolism in elderly patients with pituitary disease. Journal of Clinical Endocrinology and Metabolism 85 4104-4112.

Franco C, Veldhuis JD, Iranmanesh A, Brandberg J, Lönn L, Andersson B, Bengtsson B, Svensson J \& Johannsson G 2006 Thigh intermuscular fat is inversely associated with spontaneous GH release in post-menopausal women with abdominal obesity. European Journal of Endocrinology 155 261-268.

Ghiron LJ, Thompson JL, Holloway L, Hintz RL, Butterfield GE, Hoffman AR \& Marcus R 1995 Effects of recombinant insulin-like growth factor-I and growth hormone on bone turnover in elderly women. Journal of Bone and Mineral Research 10 1844-1852.

Gibney J, Wallace JD, Spinks T, Schnorr L, Ranicar A, Cuneo RC, Lockhart S, Burnand KG, Salomon F, Sonksen PH et al. 1999 The effects of 10 years of recombinant human growth hormone $(\mathrm{GH})$ in adult $\mathrm{GH}$-deficient patients. Journal of Clinical Endocrinology and Metabolism 84 2596-2602.

Giorgetti S, Ballotti R, Kowalski-Chauvel A, Tartare S \& Van Obberghen E 1993 The insulin and insulin-like growth factor-I receptor substrate IRS-1 associates with and activates phosphatidylinositol 3-kinase in vitro. Journal of Biological Chemistry 268 7358-7364.

Giorgino F, Pedrini MT, Matera L \& Smith RJ 1997 Specific increase in p85alpha expression in response to dexamethasone is associated with inhibition of insulin-like growth factor-I stimulated phosphatidylinositol 3-kinase activity in cultured muscle cells. Journal of Biological Chemistry 272 7455-7463.

Giustina A, Mazziotti G \& Canalis E 2008 Growth hormone, insulin-like growth factors, and the skeleton. Endocrine Reviews 29 535-559.

Goldspink G 2004 Age-related loss of skeletal muscle function; impairment of gene expression. Journal of Musculoskeletal \& Neuronal Interactions 4 143-147.

Goldspink G 2007 Loss of muscle strength during aging studied at the gene level. Rejuvenation Research 10 397-405.

Götherström G, Bengtsson B, Sunnerhagen KS, Johannsson G \& Svensson J 2005 The effects of five-year growth hormone replacement therapy on muscle strength in elderly hypopituitary patients. Clinical Endocrinology 62 105-113

Götherström G, Elbornsson M, Stibrant-Sunnerhagen K, Bengtsson B, Johannsson G \& Svensson J 2009 Ten years of growth hormone (GH) replacement normalizes muscle strength in GH-deficient adults. Journal of Clinical Endocrinology and Metabolism 94 809-816.

Grey A, Chen Q, Xu X, Callon K \& Cornish J 2003 Parallel phosphatidylinositol-3 kinase and p42/44 mitogen-activated protein kinase signaling pathways subserve the mitogenic and antiapoptotic actions of insulin-like growth factor I in osteoblastic cells. Endocrinology 144 4886-4893.

Grinspoon S, Baum H, Lee K, Anderson E, Herzog D \& Klibanski A 1996 Effects of short-term recombinant human insulin-like growth factor I administration on bone turnover in osteopenic women with anorexia nervosa. Journal of Clinical Endocrinology and Metabolism 81 3864-3870.

Haddad F \& Adams GR 2006 Aging-sensitive cellular and molecular mechanisms associated with skeletal muscle hypertrophy. Journal of Applied Physiology 100 1188-1203. 
Hagen JL, Krause DJ, Baker DJ, Fu MH, Tarnopolsky MA \& Hepple RT 2004 Skeletal muscle aging in F344BN F1-hybrid rats: I. Mitochondrial dysfunction contributes to the age-associated reduction in $\mathrm{VO}_{2}$ max Journals of Gerontology Series A: Biological Sciences and Medical Sciences 59 1099-1110.

Hajian-Tilaki KO \& Heidari B 2007 Prevalence of obesity, central obesity and the associated factors in urban population aged 20-70 years, in the north of Iran: a population-based study and regression approach. Obesity Reviews $\mathbf{8}$ $3-10$.

Hameed M, Lange KHW, Andersen JL, Schjerling P, Kjaer M, Harridge SDR \& Goldspink G 2004 The effect of recombinant human growth hormone and resistance training on IGF-I mRNA expression in the muscles of elderly men. Journal of Physiology 555 231-240.

Hansen JA, Lindberg K, Hilton DJ, Nielsen JH \& Billestrup N 1999 Mechanism of inhibition of growth hormone receptor signaling by suppressor of cytokine signaling proteins. Molecular Endocrinology 13 1832-1843.

Hartman ML, Faria AC, Vance ML, Johnson ML, Thorner MO \& Veldhuis JD 1991 Temporal structure of in vivo growth hormone secretory events in humans. American Journal of Physiology 260 E101-E110.

Hermann M \& Berger P 2001 Hormonal changes in aging men: a therapeutic indication? Experimental Gerontology 36 1075-1082.

Ho KY, Veldhuis JD, Johnson ML, Furlanetto R, Evans WS, Alberti KG \& Thorner MO 1988 Fasting enhances growth hormone secretion and amplifies the complex rhythms of growth hormone secretion in man. Journal of Clinical Investigation 81 968-975.

Hoffman AR, Kuntze JE, Baptista J, Baum HBA, Baumann GP, Biller BMK, Clark RV, Cook D, Inzucchi SE, Kleinberg D et al. 2004 Growth hormone $(\mathrm{GH})$ replacement therapy in adult-onset gh deficiency: effects on body composition in men and women in a double-blind, randomized, placebo-controlled trial. Journal of Clinical Endocrinology and Metabolism 89 2048-2056.

Hou P, Sato T, Hofstetter W \& Foged NT 1997 Identification and characterization of the insulin-like growth factor I receptor in mature rabbit osteoclasts. Journal of Bone and Mineral Research 12 534-540.

Johannsson G \& Bengtsson BA 1999 Growth hormone and the metabolic syndrome. Journal of Endocrinological Investigation 22 41-46.

Jonsson KB, Wiberg K, Ljunghall S \& Ljunggren O 1996 Insulin-like growth factor I does not stimulate bone resorption in cultured neonatal mouse calvarial bones. Calcified Tissue International 59 366-370.

Katic M \& Kahn CR 2005 The role of insulin and IGF-1 signaling in longevity. Cellular and Molecular Life Sciences 62 320-343.

Krakauer JC, McKenna MJ, Rao DS \& Whitehouse FW 1997 Bone mineral density in diabetes. Diabetes Care 20 1339-1340.

Kveiborg M, Flyvbjerg A, Rattan SI \& Kassem M 2000 Changes in the insulin-like growth factor-system may contribute to in vitro age-related impaired osteoblast functions. Experimental Gerontology 35 1061-1074.

Lai KV, Gonzalez M, Poueymirou WT, Kline WO, Na E, Zlotchenko E, Stitt TN, Economides AN, Yancopoulos GD \& Glass DJ 2004 Conditional activation of akt in adult skeletal muscle induces rapid hypertrophy. Molecular and Cellular Biology 24 9295-9304.

Landin-Wilhelmsen K, Wilhelmsen L, Lappas G, Rosén T, Lindstedt G, Lundberg PA \& Bengtsson BA 1994 Serum insulin-like growth factor I in a random population sample of men and women: relation to age, sex, smoking habits, coffee consumption and physical activity, blood pressure and concentrations of plasma lipids, fibrinogen, parathyroid hormone and osteocalcin. Clinical Endocrinology 41 351-357.

Laron Z 1999 The essential role of IGF-I: lessons from the long-term study and treatment of children and adults with Laron syndrome. Journal of Clinical Endocrinology and Metabolism 84 4397-4404.

Laviola L, Natalicchio A \& Giorgino F 2007 The IGF-I signaling pathway. Current Pharmaceutical Design 13 663-669.

Laviola L, Natalicchio A, Perrini S \& Giorgino F 2008 Abnormalities of IGF-I signaling in the pathogenesis of diseases of the bone, brain, and fetoplacental unit in humans. American Journal of Physiology. Endocrinology and Metabolism 295 E991-E999.
Léger B, Derave W, De Bock K, Hespel P \& Russell AP 2008 Human sarcopenia reveals an increase in SOCS-3 and myostatin and a reduced efficiency of Akt phosphorylation. Rejuvenation Research 11 163-175B.

Li M, Li C \& Parkhouse WS 2003 Age-related differences in the des IGF-Imediated activation of Akt-1 and p70 S6K in mouse skeletal muscle. Mechanisms of Ageing and Development 124 771-778.

Luo J, Sobkiw CL, Hirshman MF, Logsdon MN, Li TQ, Goodyear LJ \& Cantley LC 2006 Loss of class IA PI3K signaling in muscle leads to impaired muscle growth, insulin response, and hyperlipidemia. Cell Metabolism 3 355-366.

Marcell TJ, Harman SM, Urban RJ, Metz DD, Rodgers BD \& Blackman MR 2001 Comparison of GH, IGF-I, and testosterone with mRNA of receptors and myostatin in skeletal muscle in older men. American Journal of Physiology. Endocrinology and Metabolism 281 E1159-E1164.

Mathews LS, Norstedt G \& Palmiter RD 1986 Regulation of insulinlike growth factor I gene expression by growth hormone. PNAS $\mathbf{8 3}$ 9343-9347.

McPherron AC, Lawler AM \& Lee SJ 1997 Regulation of skeletal muscle mass in mice by a new TGF-beta superfamily member. Nature $38783-90$.

Migliaccio E, Giorgio M, Mele S, Pelicci G, Reboldi P, Pandolfi PP, Lanfrancone L \& Pelicci PG 1999 The p66shc adaptor protein controls oxidative stress response and life span in mammals. Nature 402 309-313.

Møller N \& Jørgensen JOL 2009 Effects of growth hormone on glucose, lipid, and protein metabolism in human subjects. Endocrine Reviews $\mathbf{3 0}$ 152-177.

Møller N, Gormsen LC, Schmitz O, Lund S, Jørgensen JOL \& Jessen N 2009 Free fatty acids inhibit growth hormone/signal transducer and activator of transcription-5 signaling in human muscle: a potential feedback mechanism. Journal of Clinical Endocrinology and Metabolism 94 2204-2207.

Moran A, Jacobs DRJ, Steinberger J, Cohen P, Hong C, Prineas R \& Sinaiko AR 2002 Association between the insulin resistance of puberty and the insulin-like growth factor-I/growth hormone axis. Journal of Clinical Endocrinology and Metabolism 87 4817-4820.

Moutoussamy S, Renaudie F, Lago F, Kelly PA \& Finidori J 1998 Grb10 identified as a potential regulator of growth hormone $(\mathrm{GH})$ signaling by cloning of GH receptor target proteins. Journal of Biological Chemistry 273 15906-15912.

Natalicchio A, Laviola L, De Tullio C, Renna LA, Montrone C, Perrini S, Valenti G, Procino G, Svelto M \& Giorgino F 2004 Role of the p66Shc isoform in insulin-like growth factor I receptor signaling through MEK/Erk and regulation of actin cytoskeleton in rat myoblasts. Journal of Biological Chemistry 279 43900-43909.

Nemoto S \& Finkel T 2002 Redox regulation of forkhead proteins through a p66shc-dependent signaling pathway. Science 295 2450-2452.

Nicolas V, Prewett A, Bettica P, Mohan S, Finkelman RD, Baylink DJ \& Farley JR 1994 Age-related decreases in insulin-like growth factor-I and transforming growth factor-beta in femoral cortical bone from both men and women: implications for bone loss with aging. Journal of Clinical Endocrinology and Metabolism 78 1011-1016.

Nilsson A, Swolin D, Enerback S \& Ohlsson C 1995 Expression of functional growth hormone receptors in cultured human osteoblast-like cells. Journal of Clinical Endocrinology and Metabolism 80 3483-3488.

Ogata N, Chikazu D, Kubota N, Terauchi Y, Tobe K, Azuma Y, Ohta T, Kadowaki T, Nakamura K \& Kawaguchi H 2000 Insulin receptor substrate1 in osteoblast is indispensable for maintaining bone turnover. Journal of Clinical Investigation 105 935-943.

Ohlsson C, Mohan S, Sjögren K, Tivesten A, Isgaard J, Isaksson O, Jansson J \& Svensson J 2009 The role of liver-derived insulin-like growth factor-I. Endocrine Reviews 30 494-535.

Pelicci G, Lanfrancone L, Grignani F, McGlade J, Cavallo F, Forni G, Nicoletti I, Grignani F, Pawson T \& Pelicci PG 1992 A novel transforming protein (SHC) with an $\mathrm{SH} 2$ domain is implicated in mitogenic signal transduction. Cell 70 93-104.

Perrini S, Carreira MC, Conserva A, Laviola L \& Giorgino F 2008a Metabolic implications of growth hormone therapy. Journal of Endocrinological Investigation 31 79-84. 
Perrini S, Natalicchio A, Laviola L, Cignarelli A, Melchiorre M, De Stefano F Caccioppoli C, Leonardini A, Martemucci S, Belsanti G et al. 2008 b Abnormalities of insulin-like growth factor-I signaling and impaired cell proliferation in osteoblasts from subjects with osteoporosis. Endocrinology 149 1302-1313.

Petley T, Graff K, Jiang W, Yang H \& Florini J 1999 Variation among cell types in the signaling pathways by which IGF-I stimulates specific cellular responses. Hormone and Metabolic Research 31 70-76.

Pfeilschifter J, Diel I, Pilz U, Brunotte K, Naumann A \& Ziegler R 1993 Mitogenic responsiveness of human bone cells in vitro to hormones and growth factors decreases with age. Journal of Bone and Mineral Research 8 707-717.

Reijnders CMA, Bravenboer N, Holzmann PJ, Bhoelan F, Blankenstein MA \& Lips P 2007 In vivo mechanical loading modulates insulin-like growth factor binding protein-2 gene expression in rat osteocytes. Calcified Tissue International 80 137-143.

Robertson K, Kopchick JJ \& Liu J 2006 Growth hormone receptor gene deficiency causes delayed insulin responsiveness in skeletal muscles without affecting compensatory islet cell overgrowth in obese mice. American Journal of Physiology. Endocrinology and Metabolism 291 E491-E498.

Rommel C, Bodine SC, Clarke BA, Rossman R, Nunez L, Stitt TN, Yancopoulos GD \& Glass DJ 2001 Mediation of IGF-1-induced skeletal myotube hypertrophy by PI(3)K/Akt/mTOR and PI(3)K/Akt/GSK3 pathways. Nature Cell Biology 3 1009-1013.

Rosen CJ 2004 Insulin-like growth factor I and bone mineral density: experience from animal models and human observational studies. Best Practice \& Research. Clinical Endocrinology \& Metabolism 18 423-435.

Rosenfeld RG \& Hwa V 2009 The growth hormone cascade and its role in mammalian growth. Hormone Research 71 (Suppl 2) 36-40.

Rössner S 2001 Obesity in the elderly - a future matter of concern? Obesity Reviews 2 183-188.

Ryall JG, Schertzer JD \& Lynch GS 2008 Cellular and molecular mechanisms underlying age-related skeletal muscle wasting and weakness. Biogerontology 9 213-228.

Sanders EJ, Parker E \& Harvey S 2006 Retinal ganglion cell survival in development: mechanisms of retinal growth hormone action. Experimental Eye Research 83 1205-1214.

Sandri M, Sandri C, Gilbert A, Skurk C, Calabria E, Picard A, Walsh K, Schiaffino S, Lecker SH \& Goldberg AL 2004 Foxo transcription factors induce the atrophy-related ubiquitin ligase atrogin-1 and cause skeletal muscle atrophy. Cell 117 399-412.

Schertzer JD, Ryall JG \& Lynch GS 2006 Systemic administration of IGF-I enhances oxidative status and reduces contraction-induced injury in skeletal muscles of $\mathrm{mdx}$ dystrophic mice. American Journal of Physiology. Endocrinology and Metabolism 291 E499-E505.

Sell C, Ptasznik A, Chang CD, Swantek J, Cristofalo VJ \& Baserga R 1993 IGF-1 receptor levels and the proliferation of young and senescent human fibroblasts. Biochemical and Biophysical Research Communications 194 259-265.

Short KR, Moller N, Bigelow ML, Coenen-Schimke J \& Nair KS 2008 Enhancement of muscle mitochondrial function by growth hormone. Journal of Clinical Endocrinology and Metabolism 93 597-604.

Slootweg MC, van Buul-Offers SC, Herrmann-Erlee MP, van der Meer JM \& Duursma SA 1988 Growth hormone is mitogenic for fetal mouse osteoblasts but not for undifferentiated bone cells. Journal of Endocrinology 116 R $11-R 13$

Slootweg MC, Salles JP, Ohlsson C, de Vries CP, Engelbregt MJ \& Netelenbos JC 1996 Growth hormone binds to a single high affinity receptor site on mouse osteoblasts: modulation by retinoic acid and cell differentiation. Journal of Endocrinology 150 465-472.

Sotiropoulos A, Ohanna M, Kedzia C, Menon RK, Kopchick JJ, Kelly PA \& Pende M 2006 Growth hormone promotes skeletal muscle cell fusion independent of insulin-like growth factor 1 up-regulation. PNAS 103 7315-7320.
Svensson J, Sunnerhagen KS \& Johannsson G 2003 Five years of growth hormone replacement therapy in adults: age- and gender-related changes in isometric and isokinetic muscle strength. Journal of Clinical Endocrinology and Metabolism 88 2061-2069.

Szulc P, Beck TJ, Marchand F \& Delmas PD 2005 Low skeletal muscle mass is associated with poor structural parameters of bone and impaired balance in elderly men - the MINOS study. Journal of Bone and Mineral Research 20 $721-729$.

Tanaka H, Quarto R, Williams S, Barnes J \& Liang CT 1994 In vivo and in vitro effects of insulin-like growth factor-I (IGF-I) on femoral mRNA expression in old rats. Bone 15 647-653.

Taylor WE, Bhasin S, Artaza J, Byhower F, Azam M, Willard DHJ, Kull FCJ \& Gonzalez-Cadavid N 2001 Myostatin inhibits cell proliferation and protein synthesis in C2C12 muscle cells. American Journal of Physiology. Endocrinology and Metabolism 280 E221-E228.

Vanderkuur JA, Butch ER, Waters SB, Pessin JE, Guan KL \& Carter-Su C 1997 Signaling molecules involved in coupling growth hormone receptor to mitogen-activated protein kinase activation. Endocrinology 138 4301-4307.

Veldhuis JD \& Iranmanesh A 1996 Physiological regulation of the human growth hormone (GH)-insulin-like growth factor type I (IGF-I) axis: predominant impact of age, obesity, gonadal function, and sleep. Sleep 19 S221-S224.

Wilkes EA, Selby AL, Atherton PJ, Patel R, Rankin D, Smith K \& Rennie MJ 2009 Blunting of insulin inhibition of proteolysis in legs of older subjects may contribute to age-related sarcopenia. American Journal of Clinical Nutrition 90 1343-1350.

Woodhouse LJ, Mukherjee A, Shalet SM \& Ezzat S 2006 The influence of growth hormone status on physical impairments, functional limitations, and health-related quality of life in adults. Endocrine Reviews 27 287-317.

Wu M, Katta A, Gadde MK, Liu H, Kakarla SK, Fannin J, Paturi S, Arvapalli RK, Rice KM, Wang Y et al. 2009 Aging-associated dysfunction of Akt/protein kinase B: S-nitrosylation and acetaminophen intervention. PLoS ONE 4 e6430.

Yamauchi K \& Pessin JE 1994 Insulin receptor substrate-1 (IRS1) and Shc compete for a limited pool of Grb2 in mediating insulin downstream signaling. Journal of Biological Chemistry 269 31107-31114.

Yamauchi T, Ueki K, Tobe K, Tamemoto H, Sekine N, Wada M, Honjo M, Takahashi M, Takahashi T, Hirai H et al. 1997 Tyrosine phosphorylation of the EGF receptor by the kinase Jak2 is induced by growth hormone. Nature 390 91-96.

Zhang W, Lee JC, Kumar S \& Gowen M 1999 ERK pathway mediates the activation of Cdk2 in IGF-1-induced proliferation of human osteosarcoma MG-63 cells. Journal of Bone and Mineral Research 14 528-535.

Zhao H, Liu J, Ning G, Zhao Y, Chen Y, Sun L, Zhang L, Xu M \& Chen J 2008 Relationships between insulin-like growth factor-I (IGF-I) and OPG, RANKL, bone mineral density in healthy Chinese women. Osteoporosis International 19 221-226.

Zhu X, Hadhazy M, Wehling M, Tidball JG \& McNally EM 2000 Dominant negative myostatin produces hypertrophy without hyperplasia in muscle. FEBS Letters 474 71-75.

Zhu T, Goh EL, Graichen R, Ling L \& Lobie PE 2001 Signal transduction via the growth hormone receptor. Cellular Signalling 13 599-616.

Zhu T, Ling L \& Lobie PE 2002 Identification of a JAK2-independent pathway regulating growth hormone (GH)-stimulated p44/42 mitogenactivated protein kinase activity. GH activation of $\mathrm{Ral}$ and phospholipase $\mathrm{D}$ is Src-dependent. Journal of Biological Chemistry 277 45592-45603.

\section{Received in final form 31 January 2010 \\ Accepted 2 March 2010 \\ Made available online as an Accepted Preprint 2 March 2010}

